\title{
Optimization of Planetary Gear Box for High reduction ratio
}

\author{
S.B.Nandeppagoudar ${ }^{1,2}$, S.N.Shaikh ${ }^{1}$, S.H.Gawande ${ }^{1}$ \\ ${ }^{I}$ (Department of Mechanical Engineering, M.E.S. College of Engineering, Pune, S.P. Pune University, India) \\ ${ }_{2}^{2}$ (Managing Director, Naveen Hydro-controls, MIDC Bhosari, Pune, India)
}

\begin{abstract}
Planetary gear boxes are used in different applications like power transmitting systems of machine tools and so on. Planetary gear boxes have the advantages of high power transmiting ability, large reduction in a small volume, multi stage reduction combinations, and axial direction of power path. Gears in planetary gear boxes sometimes get short life due to wear and breakage by repetitive load during operation time. In this work, a design evaluation for the high power transmitting through planetary gear box at low space application was performed to ensure the gears' stability and durability during operation time.
\end{abstract}

Keywords-Design for compact and high reduction power transmitting, Durability, planetary gear box, Reduction gear, Ring gear, Sun gear, Stability.

\section{INTRODUCTION}

Planetary gear systems are used in various applications. These gear systems are in high demand for efficient manufacturing in advance industrial applications and automations such as power transmission in process equipment, material handling equipment, metal cutting and metal forming machineries etc. Planetary gear systems are capable of transmitting the highest torque with the highest performance and high reduction ratios. The planetary gear systems parts are likely to wear and breakage during its normal working cycle by repetitive load in operations. Validation of the planetary gear system is advisable, experimental validation is preferred which can be correlated with theoretical or analytical validation further. There are several software packages available for the analytical validation of the gear train performance. Now a days light weight and compact gearbox design with high load carrying capacity and compact in size are the main requirements of customers. Today we have very high expectations for precision and accuracy in any and every products. The gear system in any application can be designed as per AGMA or any international standards. For verity of industrial engineering challenges gears with single or multi stages, with more types of connections and mountings are available. Different kind of tooth profiles and gears are exists in the industries. Like spur gears and helical gears Bevel gears and so on. Fig.1 shows the basic layout of the planetary gear system. Which consists of four elements as follows,

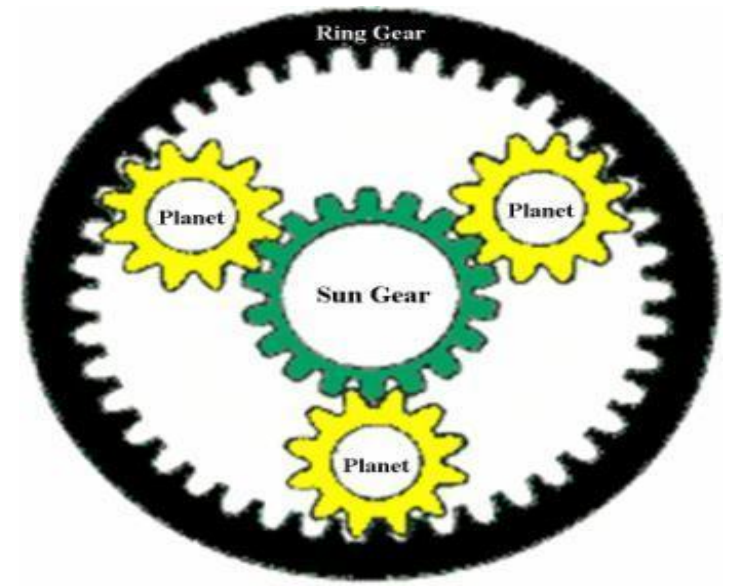

Fig.1 Basic Layout Planetary Gear

- $\quad$ Sun Gear - Located at the center, this gear is considered as a pinion for basic gear considerations. Sun gear is smaller in section compared to planet gears. Profile of the sun gear is different from the profile of that 
planet gears in overall dimensions though tooth profile remains same for the basic principle of gear teeth engagement. Input shaft is connected to sun gear

- Planet Gear - Planet gears are considered as gears engaged with sun as a pinion in the system. No. of planet gears can be varied such as three or four based on the speed and torque requirement of the system plane gears are driven by the sun gear and they revolve around the sun gear in the closed and well defined envelope.

- $\quad$ Ring Gear - Ring gear is the boundary of an envelope defined for the packaging of the sun and the planetary gear. Out of three gear components, sun, planet and ring, the ring is the robust design. These gears are also termed as annulus in some of the literatures.

- Arm - Shaft of sun gears and planet gears are connected internally with arms. No. of arms required are equal to no. of planet gears in the system. Arm basically connects the shafts of the sun gear and planetary gears.

Sun pivoted at the center, ring gears at the outer envelope and these two connected by planet gears is the basic schematic of the planetary gear system. Planetary gear system is the potential gear drive in industrial and automobile industry where the high torque demand is increasing with space constraints. Planetary gear system is capable of generating high torque within the smaller space of the overall system compared to any other available gear system. Torque intensity is the key for the planetary gear system and this can be increased by increasing the number of planet gears in the system. If we want to compare the planetary gear box system with the spur gear box system, three planet gear box can provide three times more torque than a single spur gear system almost within the same space constraints.

Lots of researchers have done study on reducing size (In diameter) of the planetary gear box. L.Chang et.al. [1] studied the robust model stiffness of cylindrical gears \& pinions. He studied that reduced rim and web thickness results in smaller mesh stiffness.S.H.Gawande,S.N.Shaikh [2] in their paper performed experimental work to study noise level reduction in planetary gear set by phasing.J.Stefanović Marjanovic [3] studied practical approach to the optimization of planetary gear trains with "spur gears" In his study he presented the selection of optimal gear trains and also selection of optimal position for shaft axes of gears trains with "spur gears". In this the volume of the planetary gear trains with "spur gears" is drastically reduced by 23\%.S.H.Gawande,S.N.Shaikh[4] in their paper studied Noise level reduction in planetary gear set.Dr. A.Kapelevich [5] did design analysis of typical differential Epicycle gear mesh which gives heist gear ratios which is suitable for very low torque robotics application This paper provides an analysis of such uncommon gear drive arrangements and defines their major parameters, limitations, and gear ratio maximization approaches. Study conducted by O. Bunga al. [6] on mass optimization of design of two stage coaxial high speed reducer with GA (Genetic Algorithm) compared in the traditional design of speed reducer with optimized design by GA. In this study the compromise between the service life and mass was presented \& they concluded and understood that the required service life needs to be sacrificed with some percentage (75\%) for a $2.5 \mathrm{~kg}$ saving (roughly 7\%).One more researcher Bernd-Robert Höhn, K.Stahl and P.Gwinner [7] also conducted and presented a good study on light weight design of planetary gears box transmission. Syed Ibrahim Dilawer [8] conducted study on optimum design of the planetary gear train with the load analysis by varying the modules for all the gears for mainly 3 different power levels $10 \mathrm{HP}, 20 \mathrm{HP} \& 15 \mathrm{HP}$. Cheon-Jae Bahk et al. [9] studied on a nonlinear dynamic model of any planetary gear which is having tooth profile modification (TPM).

From the Literature survey it has been noticed that large amount of efforts have been put to optimize the radial size of the gear box. The efforts for reducing the axial length of the gear box keep the load carrying capacity same gives very good vertical space reduction.

\section{PROBLEM FORMULATION AND OBJECTIVE}

The main motivation of this research work is to indigenization of high precision gear box for Indian machine tool industries and promoting Indian skill at global platform. In many engineering applications space and load carrying capacity is complex phenomenon in which lot of money is wasted due to non-availability of required power transmission elements such as Gear boxes at regional places. Is consumes not only money but lot of development time, due to which global competition is very tough. This motivated us to conduct research in Design \& optimization of compact Planetary Gear Box for high reduction and the strength. The objective of the research work is to localize this product and served to the Indian industries. Aim of this project is to Design, manufacture and analyse the Planetary Gear and supply to the industries.The aim of this work is to re design, manufacture and analyse the Planetary Gear box as per requirement In order to acquire the aim following objectives are set:

1. To redesign the planetary gear box which will suitable for machine tool application where the space and load constrains are the prime objectives. 
2. To perform high power transmission analysis in machine tools with existing gearbox and Re designed planetary gear box for stability and strength of gearing system for highest transmission capacity.

3. To compare the strength, Size, weight and torque densities of modified planetary gear train with equivalent existing designed planetary gear train.

\subsection{Essential conditions for planetary gear train:}

There are three essential conditions for the planetary gear train to transmit the power from input shaft to output shaft. These essential conditions are driven by critical parameters described below.

Condition 1:

$$
\begin{aligned}
\mathrm{Za} & =\text { No. of teeth on sun gear } \\
\mathrm{Zb} & =\text { No. of teeth on planet gear } \\
\mathrm{Zc} & =\text { No. of teeth on planet gear } \\
\mathrm{N} & =\text { No. of planets }
\end{aligned}
$$

$$
\mathrm{Zc}=\mathrm{Za}+2 \mathrm{Zb}
$$

Condition 1 enables the matching of center distance of the gears. This expression is valid for the gear system designed as standard gear system. No. of teeth on the gear can be modified by gear design based on profile shift. To fulfill this condition center distance between two gears to be matched, this given by;

$$
\mathrm{a}_{1}=\mathrm{a}_{2}
$$

Condition 2:

$$
\frac{\mathrm{Za}+\mathrm{Zc}}{\mathrm{N}}=\text { Integer }
$$

Condition 2 is requisite for placing the planet gears consistently about the sun gear. If the inconsistency in the gear placement is the required condition the we must satisfy the below expression;

$$
\frac{(\mathrm{Za}+\mathrm{zc}) \theta}{180}=\text { Integer }
$$

Where $\theta$ - half the angle between adjacent planet gears $\left(^{\circ}\right)$

Condition 3:

$$
\mathrm{Zb}+2<(Z a+Z b) \sin \frac{180}{\mathrm{~N}}
$$

Condition 3 ensures the operation of the planet gears without any interference with each other. This condition is the requisite for meeting the standard gear design where planet gears are equally placed.

These three conditions are necessary for any planetary gear train to transmit power and motion. Any of these conditions not getting satisfied will result in non-feasible planetary gear train design.

To understand these essential conditions in more detail, excel based tool is designed for this project work. Due to excel based tool, time required to validate the necessary conditions for the optimized gear train design is significantly reduced. To understand the tool used for essential condition validation an example is described here.

Table 1. Existing Gear Box Data

\begin{tabular}{|l|l|l|}
\hline Parameter & Symbol & Value \\
\hline Dia of sun gear & $\mathrm{Z}_{\mathrm{a}}$ & 20 \\
\hline Dia of planet gear & $\mathrm{Z}_{\mathrm{b}}$ & 28 \\
\hline Dia of ring gear & $\mathrm{Z}_{\mathrm{c}}$ & 76 \\
\hline No. of Planets & $\mathrm{N}$ & 3 \\
\hline
\end{tabular}

Table 1 shows the values for no. of gears on sun, planet and ring gear. These are mock values just to understand the validation of necessary conditions by excel based tool.

Condition 1

$\mathrm{Za}+2 \mathrm{Zb}=80$

As we have $\mathrm{Zc}=80$ condition 1 is satisfied.

To verify condition 2 ,

$$
\frac{\mathrm{Za}+\mathrm{Zc}}{\mathrm{N}}=\text { Integer }
$$


From table 1, it is seen that $\frac{\mathrm{Za}+\mathrm{Zc}_{\mathrm{c}}}{\mathrm{N}}=40$. As 40 is an integer condition 2 is also satisfied with the give configuration of the planetary gear.

Now to verify condition 3 ,

$$
\begin{aligned}
& \mathrm{Zb}+2<(Z a+Z b) \sin \frac{180}{\mathrm{~N}} \\
& \mathrm{Zb}+2={ }_{22}
\end{aligned}
$$

And

$(\mathrm{Za}+\mathrm{Zb}) \sin \frac{180}{\mathrm{~N}}=51.96$

As $22<51.96$

Condition 3 is also satisfied. As all three conditions are satisfied, given configuration of the planetary gear train

\begin{tabular}{|c|c|c|c|c|c|c|}
\hline & Parameter & Symbol & Value & & & \\
\hline & No. of teeth on sun gear & $\mathrm{Z}_{\mathrm{a}}$ & 40 & & & \\
\hline & No. of teeth on planet ge & $\mathrm{Z}_{\mathrm{b}}$ & 20 & & & \\
\hline & No. of teeth on ring gear & $\mathrm{Z}_{\mathrm{c}}$ & 80 & & & \\
\hline & No. of Planets & $\mathrm{N}$ & 3 & & & \\
\hline & & & & & & \\
\hline & & & & & & \\
\hline & & & & & & \\
\hline & Condition 1 & & Cond & in 2 & Condition 3 & \\
\hline $\mathrm{Zc}=\mathrm{Za}+2 \mathrm{Zb}$ & 80 & & $\mathrm{Za}+\mathrm{Zb}$ & 120 & $\mathrm{Zb}+2$ & 22 \\
\hline & & & $(\mathrm{Za}+\mathrm{Zb}) / \mathrm{N}$ & 40 & $(\mathrm{Za}+\mathrm{Zb}) \operatorname{Sin}(180 / \mathrm{N})$ & 51.96 \\
\hline & & & & & & \\
\hline & TRUE & & & TRUE & & TRUE \\
\hline
\end{tabular}
is valid.

Fig.2.Excel based calculator

Fig.4 shows the snap of excel based calculator for validating all three conditions of planetary gear train. By changing the parameters such as no. of teeth on sun, planet or ring gears or no. of planets all three conditions can be validated at once. This tool gives user a flexibility to check the primary conditions before proceeding for further design calculations.

\section{DESIGN OF PLANETARY GEAR SYTEM}

\section{Planetary gear configuration}

Planetary gear system is the potential gear drive in industrial and automobile industry where the high torque demand is increasing with space constraints. Torque intensity is the key for the planetary gear system and this can be increased by increasing the number of planet gears in the system. If we want to compare the planetary gear box system with the spur gear box system, three planet gear box can provide three times more torque than a single spur gear system almost within the same space constraints.

Grain trains are used to transmit the power or motion between two shafts. There are several other alternatives could be used for this purpose such as belt drives but gear trains have several advantageous over others

The reduction ratio of planetary gear train is the configuration arranged in a specific way as a multiplication of each stage ratios.

$$
\text { Total Gear ratio, } i=i_{1} \times i_{2} \times i_{3}
$$

In this case $i_{1}, i_{2}, i_{3}$ represents the reduction ratios at different stages of a gear system. In this system gears are connected in one configuration.For simplification integers like 3, 4, $6 \ldots$ are used.

Gear ratio configuration for existing planetary gear train;

$$
i_{1}=\frac{Z c}{Z a}+1
$$


Where $\mathrm{Zc}$ and $\mathrm{Za}$ are no. of teeth on ring gear and sun gear respectively, for the multistage gear box $i_{1}, i_{2}, i_{3} \ldots \ldots i_{n}$ are calculated and then multiplied together to get $i$, the total gear ratio.

If there is a requirement of reduction ratio as 80 to 100 in two stages from $3000 \mathrm{rpm}$ to $30 \mathrm{rpm}$;

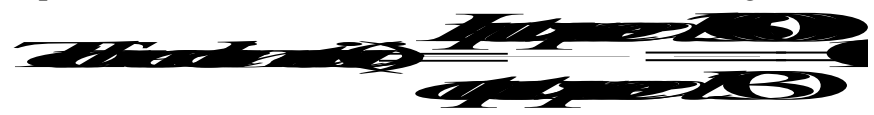

Reduction ratio of 10 in each stage can be applied to get $10 \times 10=100$ as a consolidated reduction ratio. No. of stages in gear train are based on the requirement of the reduction ratio.

\section{Existing planetary gear box configuration}

This work focuses on the planetary gear box for the CNC bending machines. Input torque and speed are generated by the stepper motor. Reduction ratio of $80-110$ is required at the output shaft. Input parameters can be varied based on the specific requirement as servo motor is used in this system as a prime mover.

Existing gear box is a three stage gear box with following specification;

$\mathrm{Za}=20=$ No. of teeth on sun gear

$$
\mathrm{Zb}=28=\text { No. of teeth on planetary gear }
$$

$\mathrm{Zc}=76=$ No. of teeth on ring gear

\section{a. Verification of essential conditions}

To verify the essential conditions to form a planetary gear system, excel based calculator is used which is discussed in chapter 3 .

Input parameters:

Table 2. Input parameters of existing Gear box

\begin{tabular}{|l|l|l|}
\hline Parameter & Symbol & Value \\
\hline Dia of sun gear & $\mathrm{Z}_{\mathrm{a}}$ & 20 \\
\hline Dia of planet gear & $\mathrm{Z}_{\mathrm{b}}$ & 28 \\
\hline Dia of ring gear & $\mathrm{Z}_{\mathrm{c}}$ & 76 \\
\hline No. of Planets & $\mathrm{N}$ & 3 \\
\hline
\end{tabular}

Condition 1

$\mathrm{Zc}=\mathrm{Za}+2 \mathrm{Zb} \quad 76$

\section{TRUE}

Condition 1 is satisfied

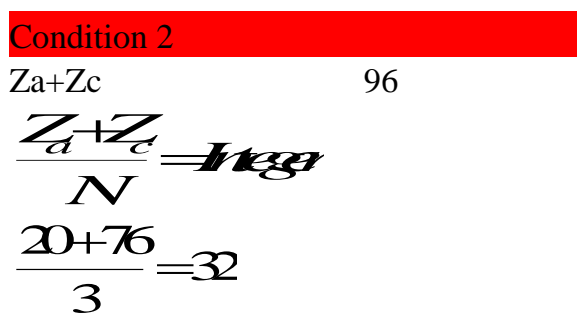

Condition 2 is satisfied

\section{TRUE}

\section{Condition 3}

$\mathrm{Zb}+2$

$(\mathrm{Za}+\mathrm{Zb}) \operatorname{Sin}(180 / \mathrm{N})$
30

41.57

\section{TRUE}


Condition 3 is satisfied

All three conditions are satisfied for this configuration.

- Calculation of gear ratio;

$i_{1}=\frac{Z c}{Z a}+1$

From the values of $Z a$ and $Z c, i_{1}=4.8$.

For three stage gear box, gear ratio $=4.8 \times 4.8 \times 4.8=110.6$

Gear ratio between Sun gear and Planet gear $=$

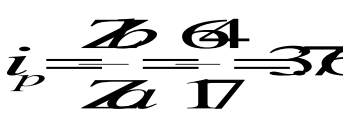

First stage speed $=797 \mathrm{rpm}$.

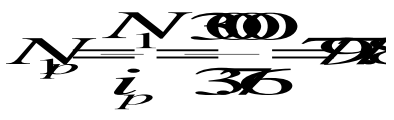

\section{b. Challenges with existing gear box}

Fig.6 shows the configuration of existing gear box fitted on the $\mathrm{CNC}$ machine. There are three stages in this gear box and the reduction ratio is 4.8 at each stage as explained in earlier section. Total gear reduction ratio is 110 .

Three stage gear box consume more space compared to two stage gear box. As the number of stages increases in the planetary gear box, clearance of the gear box with ground decreases. The working conditions where the machine is installed and the gear box is closer to the ground, it becomes challenging to operate the machine in limited clearance with the ground. There are always chances of gear box fouling with the ground.

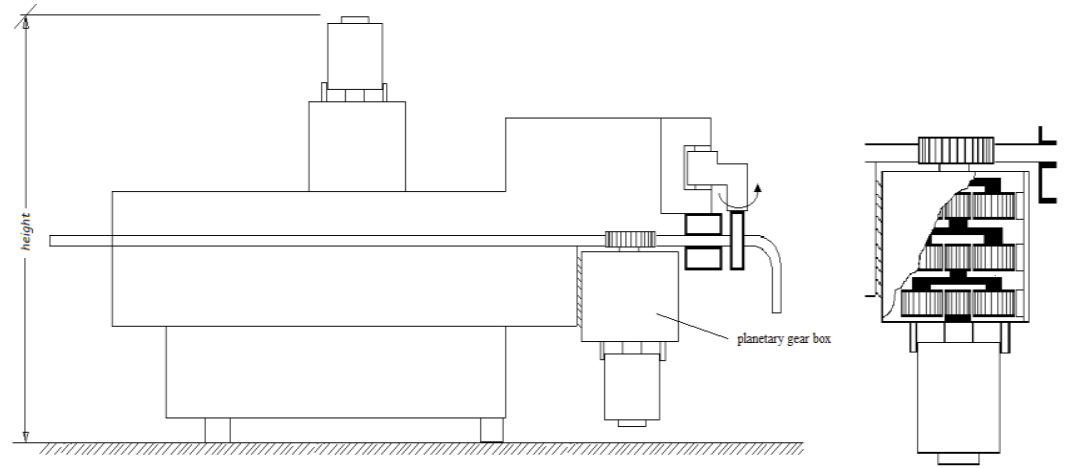

Fig.3. Existing planetary gear box arrangement

To overcome this challenge, the number of stages in gear box need to be reduced to two without compromising on the output torque and the speed. To convert a three stage gear box into two stage gear box; several considerations were done as below.

- To achieve the total gear reduction between 80-110

- The range of gear ratio is variable as input is provided by servo motor

- The output torque shall be within the range of

- The output speed shall be within the range of $2000 \mathrm{rpm}$ to $3000 \mathrm{rpm}$

The gear ratio to be attend in two stages planetary gear box is 9.53 on each stage ie total gear reduction ratio is $\mathrm{i}=\mathrm{i}_{1} \times \mathrm{i}_{2}=90.8$

In table configuration no 7 is selected for our study which will give higher reduction ratio which we are looking for.

Table 3. Available configuration of the planetary gear system

\begin{tabular}{|l|l|l|l|l|l|l|l|}
\hline $\begin{array}{l}\text { Sr.N } \\
\text { o. }\end{array}$ & $\begin{array}{l}\text { No. of theeth } \\
\text { Sun Gear }\end{array}$ & $\begin{array}{l}\text { No. of teeth } \\
\text { Planet Gear }\end{array}$ & $\begin{array}{l}\text { No. of teeth } \\
\text { Ring Gear }\end{array}$ & $\begin{array}{l}\text { Gear } \\
\text { Ratio }\end{array}$ & $\begin{array}{l}\text { No. of } \\
\text { Planets }\end{array}$ & $\begin{array}{l}\text { Check for planet } \\
\text { equi-spacing }\end{array}$ & $\begin{array}{l}\text { Check for planet } \\
\text { integral no of teeth }\end{array}$ \\
\hline 1 & 16 & 53 & 122 & 8.63 & 74.5 & 46 & 53 \\
\hline 2 & 16 & 56 & 128 & 9 & 81 & 48 & 56 \\
\hline 3 & 16 & 59 & 134 & 9.3 & 86.5 & 50 & 59 \\
\hline 4 & 17 & 55 & 127 & 8.5 & 72.25 & 48 & 55 \\
\hline 5 & 17 & 58 & 8.8 & 77.44 & 50 & 58 \\
\hline
\end{tabular}




\begin{tabular}{|l|l|l|l|l|l|l|l|}
\hline 6 & 17 & 61 & 139 & 9.18 & 84.3 & 52 & 61 \\
\hline $\mathbf{7}$ & $\mathbf{1 7}$ & $\mathbf{6 4}$ & $\mathbf{1 4 5}$ & $\mathbf{9 . 5 3}$ & $\mathbf{9 0 . 8}$ & $\mathbf{5 4}$ & $\mathbf{6 4}$ \\
\hline
\end{tabular}

\section{Optimized planetary gear box Design description}

Spur gear reducer is shown in Fig. 7. Spur pinion $C$ is coupled with the transmission shaft of the servo motor A. Two ball bearing B \& D provides the support to the shaft. The diameter of planet and sun by one number but in reality these are 3 numbers, 38,132 and faced width are 25 and 22 respectively. $5.8 \mathrm{KW}$ at 3000 RPM is transmitted to the pinion from the servo motor. Gear ratio is $9.53 / 1$, at this ratio the power is transmitted from sun gear $\mathrm{C}$ to planet gear F and half coupling H. Fmax and Fmin are the forces on the servo motor in put shaft, while $\boldsymbol{W t}$ and $\boldsymbol{W r}$ are the tangential and radial components of the gear-tooth force $\boldsymbol{W}$. Determine loads of the shafts and their minimal diameters.

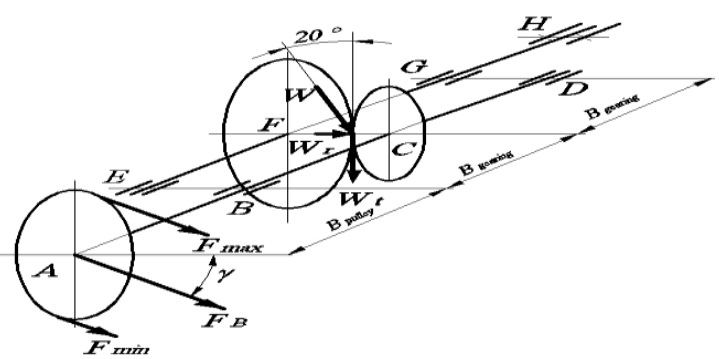

a. Calculations

Fig. 4. Sketch of a spur gear reducer

\section{- Given data :}

$\mathrm{P}=5.8 \mathrm{~kW} ; \mathrm{N}_{1}=3000 \mathrm{RPM}, \mathrm{Da}=38 \mathrm{~mm}, \mathrm{Db}=132 \mathrm{~mm}, \mathrm{i}=9.53 / 1$

$\mathrm{Ba}=25 \mathrm{~mm}, \mathrm{Bb}=22 \mathrm{~mm}, \alpha=20^{\circ}$.

\section{- Center Distance}

To find out the center distance following formula has been used

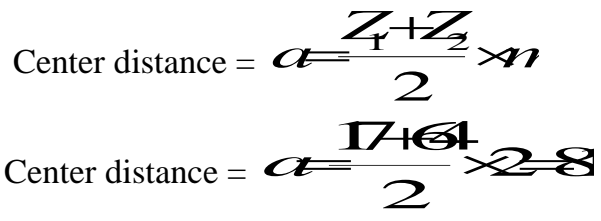

$$
\mathrm{a}=81
$$

- Module Calculation:

To find out the module of parallel axis gearing the following formula has been used.

For Spur Gears a normal module is expressed as

$$
\begin{aligned}
& m_{n}=\frac{2 \times a}{z_{1}+z_{2}} \\
& m=\frac{2 \times 81}{17+64}=2
\end{aligned}
$$

Where, $a$ is centre distance between gear axes,

$z 1, z 2$ numbers of teeth respectively for pinion(Sun gear) and gear(Planet gear).

\section{- Transmission torque}

The torque transmitted by the high speed shaft is given by:

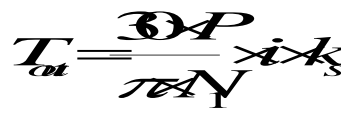

For first stage gear reducer with spur gears (see Fig.7) knowing servo motor power $\mathrm{P}=5.8 \mathrm{~kW}$, rotational speed $\mathrm{N}_{1}=3000 \mathrm{rpm}$ and gear ratio $\mathrm{i}=9.53 / 1, \mathrm{~T}_{\mathrm{in}}=16 \mathrm{~N}-\mathrm{m}$

1. Load Service : uniform,

2. operating conditions at output: moderate shock,

3. Duty hours of Gear box: $t=10 \mathrm{hrs} /$ day.

Output torque of the reducer in stage 1 is given by (11) 


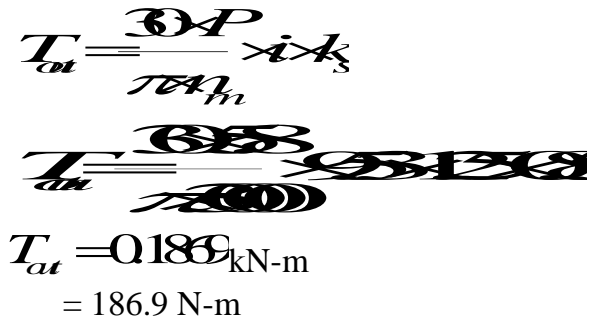

It is for one planet in a system there are 3 planets therefore the total output torque in First stage is 3 times $\mathrm{T}_{\text {out }}$

Where ks is a service factor and

$$
=560.8 \mathrm{~N}-\mathrm{m}
$$

$$
\begin{array}{r}
k_{s}=k_{a} \times k_{t} \\
k s=1.25 \times 0.85
\end{array}
$$

Where:

$k a$ is an application factor and in accordance with the Table 2 it equals 1.25 for gear input operating conditions as uniform and output operating conditions as moderate shock.

$K t$ is a duty factor and for a running time of the reducer of $3 \mathrm{hrs} /$ day equals 0.85

Similarly for Second stage the Output torque can be calculated as bellow. here we have considering two cases one based on single planet transmission three planet transmission

For Second stage gear reducer single planet with spur gears (see Fig.7) knowing servo motor power $\mathrm{P}=6.25 \mathrm{~kW}$,

Rotational speed $\mathrm{N}_{12}=314.8 \mathrm{rpm}$

Gear ratio i $=9.53 / 1$,

- Spur pinion loads

$$
\begin{aligned}
& T_{\text {at }}=1.919 \mathrm{kN}-\mathrm{m} \\
& =1919 \mathrm{~N}-\mathrm{m}
\end{aligned}
$$

Pressure angle equals $20^{\circ}$. From Fig. 7 ,

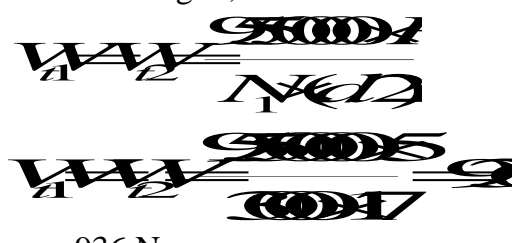

$$
=936 \mathrm{~N}
$$

VעW Wanes

$$
\begin{aligned}
& =340.8 \mathrm{~N} \\
& W=\frac{W}{\cos 20^{\circ}} \\
& W=\frac{96}{\operatorname{cose9}}
\end{aligned} \mathrm{N}
$$

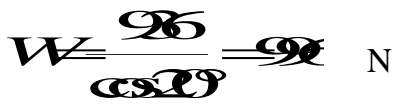

$=996 \mathrm{~N}$ 


\section{EXPERIMENTATION AND VALIDATION}

In this work present 3 stage gear box is modified to remove one stage by calculating gear ratio an by doing analytical work. To validate results obtained by analytical work experimentation is carried out.Fig.5 shows experimental set up used to carry out experimentation and Fig.6 shows experimental set up for data transfer for servo drive.

a. Experimental procedure: The re designed Planetary gear box is assembled with Servo motor and connected to KEB make servo Drive. The motor model we used is - GK6085-6AF61-FE-bz9 with rated torque is $18.5 \mathrm{Nm}$, power is $5.8 \mathrm{kw}$ at $3000 \mathrm{rpm}$.

\section{b. Experimental results}

The results were taken at no load condition and full load condition. The performance curves are shown in graph below Fig.7,8 and Fig.9,10 respectively.In full load trials max torque observed is $19.76 \mathrm{Nm}$. and Maximum Acceleration 34.66 Nm Torque is The planetary gear box is design to get 90.8:1 gear ratio therefore the output torque is $1794.2 \mathrm{Nm}(19.76 \mathrm{x} 90.8), 6.7 \%$ of its average output torque is more. In the graph Blue line indicates \% input torque of the Planetary Gear box and Red line indicates The input Speed (Servo motor) used for experimental setup.Fig- 23 and AC servo drive data transfer setup Fig-24 are shown.

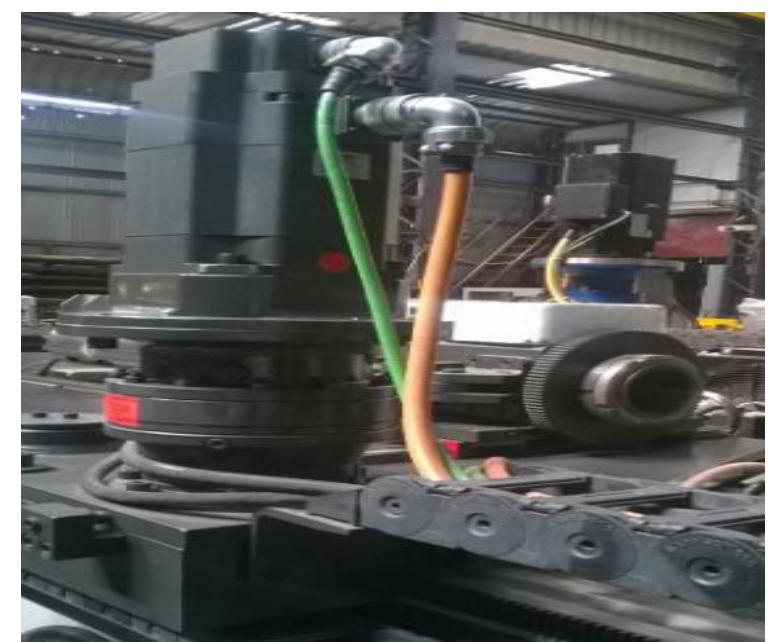

Fig.5 Experimental Setup planetary gear box and servo motor assembly

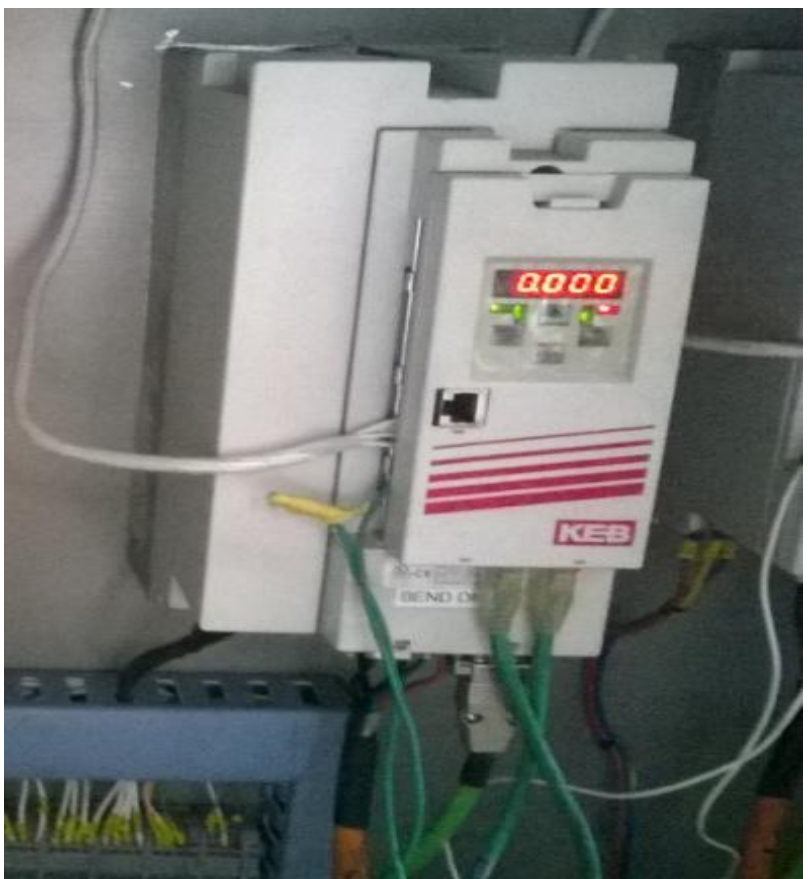

Fig 6. Experimental Setup data transfer from Servo drive 


\section{RESULTS \& DISCUSSION}

Table.5 and Table. 6 shows results obtained by analytical and experimental work.By comparing results obtained by analytical and experimental work it is seen that the results are one and the same therefore the new designed gear box is the equivalent of existing three stage planetary gear box. Hence we will validate the optimization of gear box for high reduction ratio and space is satisfied.

Table.4 Comparison of Theoretical and Experimental Results

\begin{tabular}{|l|l|l|l|}
\hline $\begin{array}{l}\text { S1 } \\
\text { No }\end{array}$ & $\begin{array}{l}\text { Parameters to be } \\
\text { compared }\end{array}$ & $\begin{array}{l}\text { Theoretical } \\
\text { calculations }\end{array}$ & $\begin{array}{l}\text { Experimental } \\
\text { results }\end{array}$ \\
\hline 1 & Tangential Load & 936 & - \\
\hline 2 & Operational speed & 314.8 & 304.5 \\
\hline
\end{tabular}

Table 5. Validation of Theoretical and Software results

\begin{tabular}{|c|c|c|c|}
\hline S1 No & Parameters to be compared & $\begin{array}{c}\text { Theoretical } \\
\text { calculations }\end{array}$ & Software results \\
\hline 1 & Output torque & 1919 & \\
\hline 2 & Operational speed 1st Stage & $797.87 \mathrm{rpm}$ & 796.87 \\
\hline 3 & Operational speed 2nd Stage & $83.7 \mathrm{rpm}$ & 83.7 \\
\hline
\end{tabular}

Table 6. Experimental results

\begin{tabular}{|c|c|c|}
\hline \multicolumn{3}{|c|}{ Scope Export (Scope_1) 1/10/2017 } \\
\hline \multicolumn{3}{|c|}{ Start of recording: 1/10/2017 7:16:22 PM } \\
\hline \multicolumn{3}{|c|}{ [0] ru09: encoder 1 speed $\langle 0\rangle$} \\
\hline \multicolumn{3}{|c|}{ [1] ru12: motor torque display $\langle 0\rangle$} \\
\hline \multicolumn{3}{|c|}{ (Device "Node_1_F5A_S") Description: "" } \\
\hline \multicolumn{3}{|c|}{ (Device "Node_1_F5A_S") Description: "" } \\
\hline Time in $\mu \mathrm{s}$ & Speed in rpm & Motor torque N-m \\
\hline 0 & 0 & -0.01 \\
\hline 1075000 & 216 & 34.66 \\
\hline 1577000 & 303 & 16.33 \\
\hline 2067000 & 298.5 & 18.61 \\
\hline 2559000 & 300 & 17.8 \\
\hline 3012000 & 298.5 & 16.15 \\
\hline 3509000 & 294 & 16.31 \\
\hline 4025000 & 304.5 & 15.23 \\
\hline 4515000 & 300 & 16.13 \\
\hline 5014000 & 304.5 & 16.84 \\
\hline 5501000 & 298.5 & 19.15 \\
\hline 6009000 & 300 & 18.91 \\
\hline 6525000 & 300 & 19.39 \\
\hline 7014000 & 300 & 19.22 \\
\hline 7527000 & 300 & 19.34 \\
\hline 8024000 & 304.5 & 18.59 \\
\hline 8510000 & 295.5 & 19.76 \\
\hline 9000000 & 300 & 18.9 \\
\hline 9165000 & 298.5 & 19.35 \\
\hline 10558000 & 0 & 2.3 \\
\hline
\end{tabular}




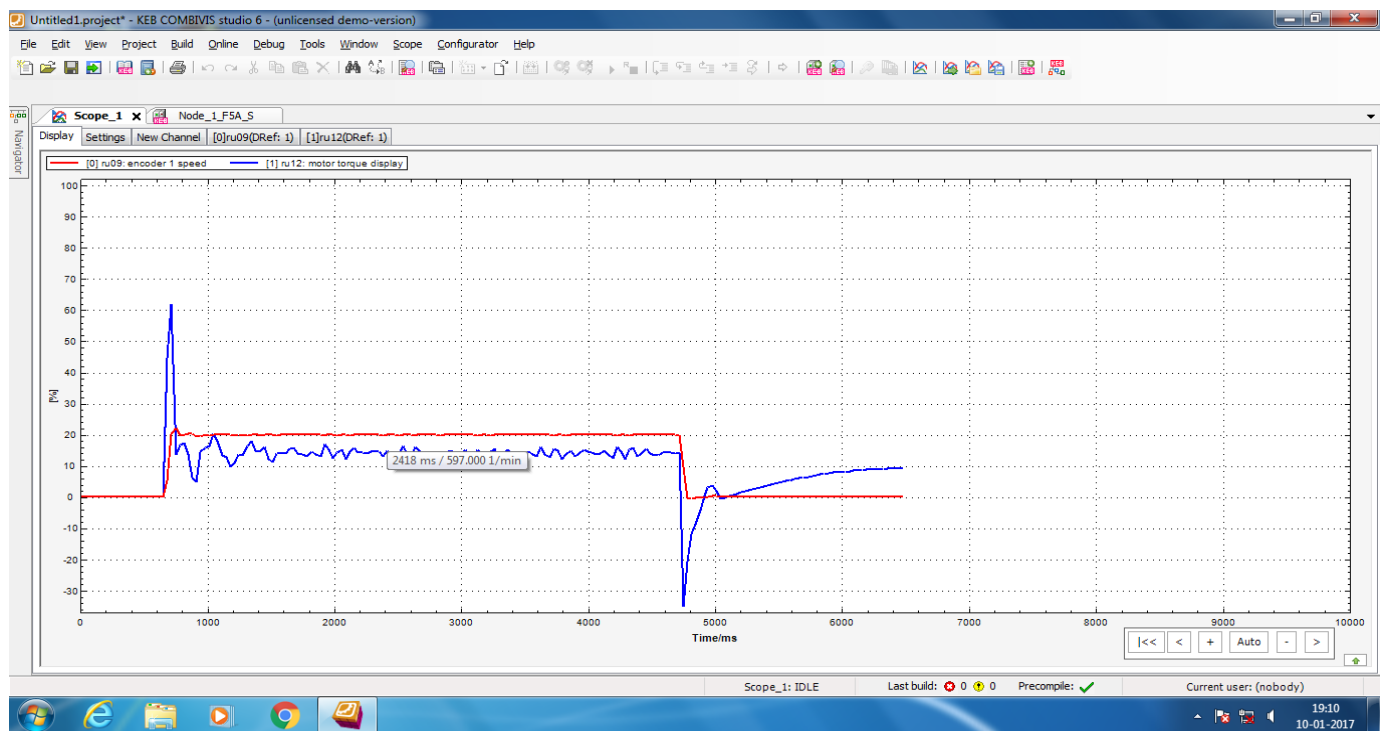

Fig 7. No-load test results KEB Servo Drive Setup for rpm

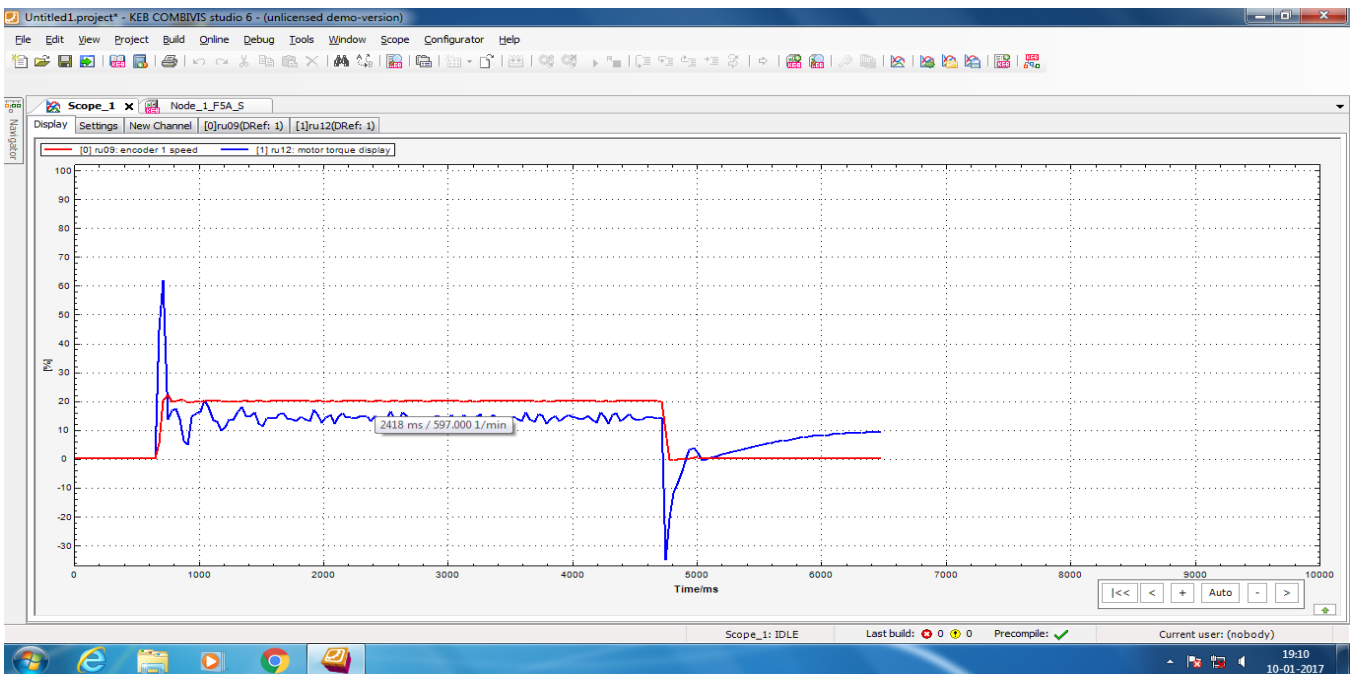

Fig 8. No-load test results KEB Servo Drive Setup for torque

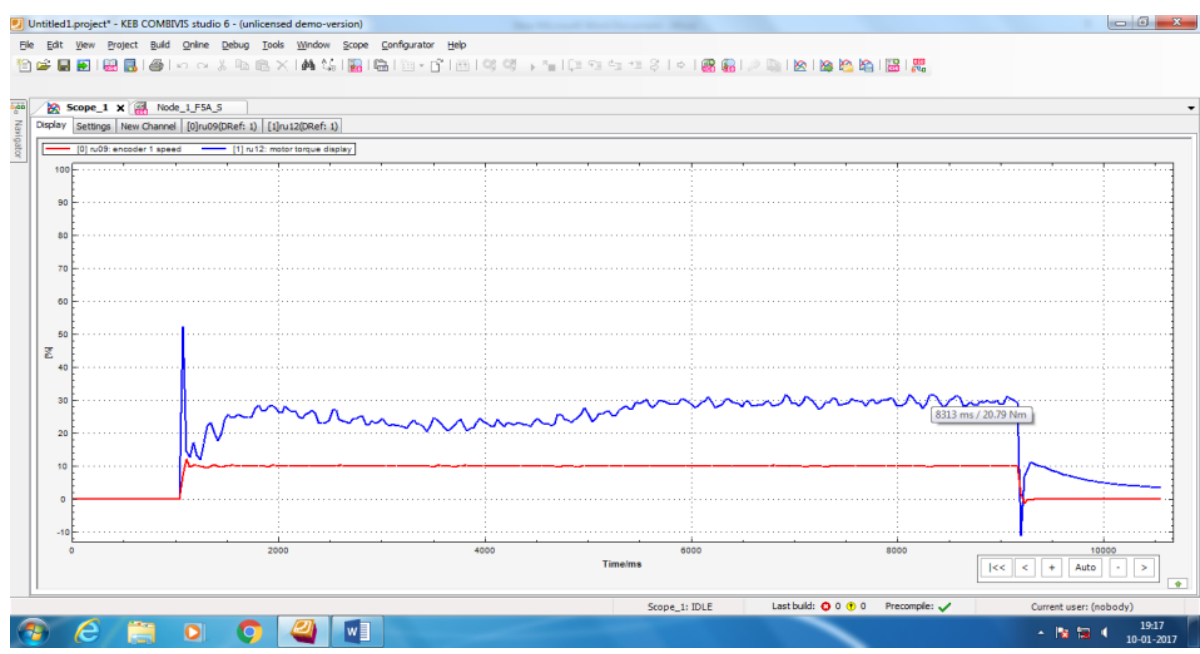

Fig 9. Load test results KEB Servo Drive Setup for rpm 


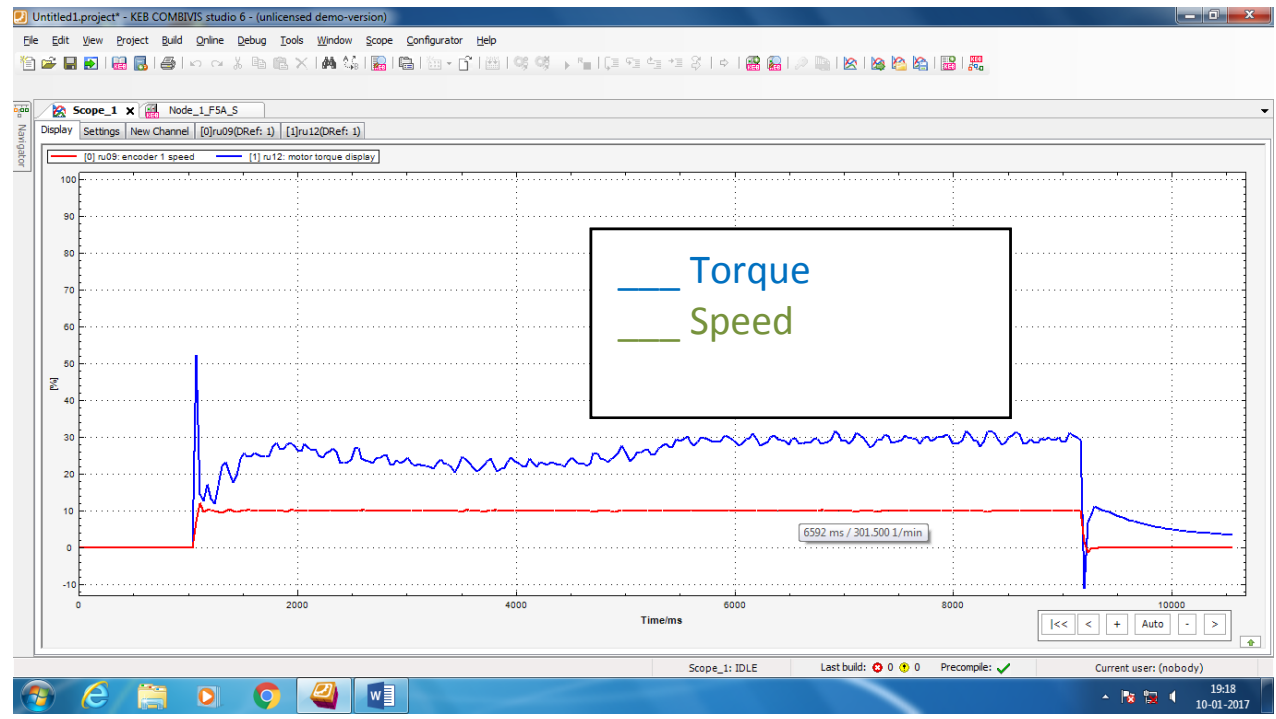

Fig 10. Load test results KEB Servo Drive Setup for torque

\section{CONCLUSION}

The objective of this work is to redesign the planetary gear box which will be suitable for machine tool application where the space and load constrains are the prime objectives. From the analytical and experimental results it is seen that,High reduction ratio 90.8 is achieved in 2 stages for planetary gear box which was in 3 stage planetary gear box. Hence planetary gear system becomes compact as one stages is eliminated. The volume of modified 2 stage planetary gear system for the given torque is $22 \%$ less than existing 3 stage planetary gear system so its cost is reduced.

\section{REFERENCES}

[1] L. Chang, G.Liu, Liyan Wu, A robust model for determining the mesh stiffness of cylindrical gears, Mechanism and Machine Theory 87,2015,93-114

[2] S.H.Gawande, S.N.Shaikh, Experimental Investigations of Noise Control in Planetary Gear by phasing,Hindawi Publishing Coorporation, Journal of Engineering ,2014, Article ID 857462, doi.org/10.1155/2014/857462

[3] J.Stefanović-Marinović , Load Allocation and Equilibrium for Planetary Gear Reducers of Earth-Pressure-Balance Shield Machine, Journal of Mechanics Engineering and Automation, 2,2012, 365-373

[4] S.H.Gawande, S.N.Shaikh, Noise Level reduction in Planetary gear set, Journal of Mechanical Design and vibration,.2(3),2014,60-62.DOI:10.12691/jmdv-2-3-1

[5] A.Kapelevich ,High Gear Ratio Epicyclic Drives Analysis, Gear Technology, 2014, 61-67

[6] O. Buiga, L.Tudose - Optimal mass minimization design of a two-stage coaxial helical speed reducer with Genetic Algorithms, Advances in Engineering Software 68,2014, 25-32

[7] Bernd-Robert Höhn, K.Stahl and P.Gwinner,Light-Weight Design for Planetary Gear Transmissions, Gear Technology, Sept. 2013, 96-103

[8] D. Ibrahim Syed,, Md. Abdul Raheem Junaidi, Dr.S.Nawazish Mehdi ,Design, Load Analysis and Optimization of Compound Epicyclic Gear Trains, American Journal of Engineering Research ISSN 2320-0936,2(10), 2013, 146-153

[9] C.Jae Bahk et al. Analytical investigation of tooth profile modification effects on Planetary gear dynamics, Mechanism and Machine theory,70, 2013, 298-319. 